\title{
Spectrum of atypical pulmonary manifestations of COVID-19 on computed tomography
}

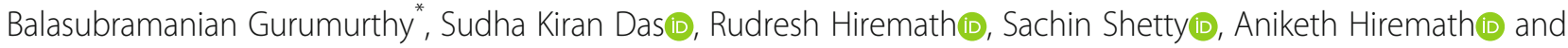 \\ Thasmai Gowda(1)
}

\begin{abstract}
Background: The typical CT manifestations of COVID-19 pneumonia include ground-glass opacity (GGO) with or without consolidation and superimposed interlobular septal thickening. These are often rounded in morphology and frequently bilateral, multilobar, posterior, peripheral, and basilar in distribution. The various atypical CT features of COVID-19 are seldom described in the literature. The study aims to enumerate the atypical pulmonary CT features in patients with COVID-19 pneumonia in correlation with the disease severity.

Results: A total of 298 confirmed cases of COVID-19 pneumonia with positive reverse transcription polymerase chain reaction (RT-PCR) who underwent chest $C T$ scans were retrospectively evaluated. The cohort included 234 (78.5\%) men and 64 (21.5\%) women and the mean age was $53.48 \pm 15.74$ years. The most common presenting symptoms were fever $[n=197(66.1 \%)]$ and cough $[n=139(46.6 \%)]$. Out of 298 cases of COVID-19 pneumonia, 218 cases (73.1\%) showed typical CT features while 63 cases (21.1\%) showed atypical CT features with concurrent classical findings and the remaining 17 cases (5.8\%) were normal. Among the atypical $C T$ features, the most common was pulmonary cysts $[n=27(9 \%)]$. The other features in the order of frequency included pleural effusion $[n=17(5.7 \%)]$, nodules $[n=13(4.3 \%)]$, bull's eye/target sign[ $n=4(1.3 \%)]$, cavitation $[n=3(1.0 \%)]$, spontaneous pneumothorax $[n=2(0.6 \%)]$, hilar lymphadenopathy $[n=2(0.6 \%)]$, spontaneous pneumo-mediastinum with subcutaneous emphysema $[n=1(0.3 \%)]$, Halo sign $[n=1(0.3 \%)]$, empyema $[n=1(0.3 \%)]$ and necrotizing pneumonia with abscess $[n=1(0.3 \%)]$.

Conclusion: CT imaging features of COVID-19 pneumonia while in a vast majority of cases is classical, atypical diverse patterns are also encountered. A comprehensive knowledge of various atypical presentations on imaging plays an important role in the early diagnosis and management of COVID-19.
\end{abstract}

Keywords: COVID-19 pneumonia, Atypical CT features, Pulmonary cysts, Bull's eye/target sign, Halo sign, Hilar lymphadenopathy, Necrotizing pneumonia

\section{Background}

Coronavirus disease 2019 (COVID-19) is caused by a severe acute respiratory syndrome coronavirus 2 (SARSCoV-2). COVID-19 is known to involve multiple organ systems with protean clinical and radiological manifestations, lungs being the most frequently involved [1].

\footnotetext{
* Correspondence: gurumurthyb@jssuni.edu.in

Department of Radiology, JSS Hospital, JSS Academy of Higher Education and Research, Ramachandra Agrahara, Mysore, Karnataka 570004, India
}

The imaging changes in COVID-19 pneumonia, though classical in a majority, a small subset of it can present with diverse pulmonary findings. Based on current literature, the typical imaging features of COVID-19 pneumonia on CT include bilateral, multilobar GGOs with/without consolidation and superimposed interlobar septal thickening $[2,3]$. They show a peripheral, posterior and basilar distribution [2].

\section{Springer Open}

() The Author(s). 2021 Open Access This article is licensed under a Creative Commons Attribution 4.0 International License, which permits use, sharing, adaptation, distribution and reproduction in any medium or format, as long as you give appropriate credit to the original author(s) and the source, provide a link to the Creative Commons licence, and indicate if changes were made. The images or other third party material in this article are included in the article's Creative Commons licence, unless indicated otherwise in a credit line to the material. If material is not included in the article's Creative Commons licence and your intended use is not permitted by statutory regulation or exceeds the permitted use, you will need to obtain permission directly from the copyright holder. To view a copy of this licence, visit http://creativecommons.org/licenses/by/4.0/. 
Apart from anecdotal case reports, the various atypical CT features of COVID-19 are less clearly described. Anecdotal occurrence of atypical CT features has been reported till date. This study aims to enumerate the spectrum of atypical features and its incidence as observed at our institute in correlation with disease severity.

\section{Methods}

\section{Study design and data collection}

This was a retrospective observational study conducted during the period from 1 July till 31 October 2020. The study included reverse-transcriptase polymerase chain reaction (RT-PCR) confirmed 298 COVID-19 pneumonia patients who were admitted to the hospital and underwent chest HRCT scan. Images were evaluated using the institutional Picture Archiving and Communication Systems (PACS) database system to assess the various imaging features in COVID-19 pneumonia cases. This study was approved by the Institutional Ethics committee.

\section{Selection criteria \\ Inclusion criteria}

Reverse-transcriptase polymerase chain reaction (RTPCR) confirmed COVID-19 pneumonia patients who underwent chest HRCT scans were considered.

\section{Exclusion criteria}

- Patients with negative RT-PCR results.

- Patients discharged to another facility during the course of illness.

\section{$\mathrm{CT}$ imaging protocol}

CT was performed using a 128-slice MDCT scanner (Ingenuity core 128 v3.5.7.25001; Philips healthcare). Patients were placed in a supine position with single breath hold. Scanning parameters were scan direction (craniocaudally), tube voltage $(120 \mathrm{KV})$, tube current $(250 \mathrm{~mA})$, slice collimation $(64 \times 0.625 \mathrm{~mm})$, width $(0.625 \times 0.625$ $\mathrm{mm})$, pitch (1), rotation time $(0.5 \mathrm{~s})$, and scan time (12.06 s). Images were reconstructed with a slice thickness of 0.5 or $1.5 \mathrm{~mm}$ and an interval of 0.5 or $1.5 \mathrm{~mm}$, respectively.

\section{CT imaging interpretation}

The images were evaluated by two senior professors and a senior resident in radiology with experience of 17 years, 15 years, and 4 years, respectively. The evaluators independently assessed the CT features using both axial CT images and multiplanar reconstruction images. The scans were first assessed whether negative or positive for
Table 1 Age distribution of the cohort

\begin{tabular}{lll}
\hline Age (in years) & Total number (out of 298) & Percentage (\%) \\
\hline $0-10$ & 1 & 0.4 \\
$11-20$ & 1 & 0.4 \\
$21-30$ & 27 & 9 \\
$31-40$ & 39 & 13 \\
$41-50$ & 51 & 17.2 \\
$51-60$ & 79 & 26.5 \\
$61-70$ & 55 & 18.5 \\
$71-80$ & 36 & 12 \\
$81-90$ & 9 & 3 \\
\hline
\end{tabular}

typical findings of COVID19 pneumonia (bilateral, multilobar, posterior peripheral ground glass opacities) as defined by the RSNA Consensus statement $[4,5]$. Later the various atypical CT imaging features were noted. Severity was assessed using CT severity score (total score out of 25) and categorized into mild (score- $<7$ ), moderate (score 7-18) and severe (score $>18$ ) as done by Saeed G A et al. [6]. The two senior professors were blinded to the outcome of the cases.

\section{Statistical analysis}

The analysis was performed using SPSS 21.0. Descriptive statistics of patients' demographics and clinical results were reported as numbers and relative frequencies. The mean differences between the groups with typical and

Table 2 Presenting symptoms of patients with COVID-19 pneumonia

\begin{tabular}{lll}
\hline Symptom & Total number & Percentage (out of 298) \\
\hline Fever & 197 & 66.1 \\
Cough & 139 & 46.6 \\
Dyspnea & 83 & 27.8 \\
Generalized weakness & 32 & 10.7 \\
Myalgia & 29 & 9.7 \\
Hemoptysis & 2 & 0.6 \\
URTI symptoms & 18 & 6.0 \\
Diarrhea & 16 & 5.3 \\
Vomiting & 8 & 2.6 \\
Easy fatigability & 33 & 11.0 \\
Palpitation & 1 & 0.3 \\
Pain abdomen & 8 & 2.6 \\
Chest pain & 12 & 4.0 \\
Headache & 10 & 3.5 \\
Loss of smell/anosmia & 5 & 1.6 \\
Loss of taste & 2 & 0.6 \\
Hemiparesis & 3 & 1.0 \\
Loss of appetite & 16 & 5.3 \\
\hline
\end{tabular}


Table 3 Comorbidities/risk factors of patients with COVID-19 pneumonia

\begin{tabular}{lll}
\hline Co-morbidities & Total number & Percentage (out of 298) \\
\hline Diabetes & 100 & 33.5 \\
Hypertension & 94 & 31.5 \\
Cardiovascular disease & 23 & 7.7 \\
Cerebrovascular disease & 4 & 1.3 \\
Chronic kidney disease & 5 & 1.6 \\
Hypothyroidism & 9 & 3.0 \\
Chronic pulmonary disease & 14 & 4.6 \\
Immunocompromised & 2 & 0.6 \\
Others & 3 & 1.0 \\
\hline
\end{tabular}

atypical CT features were subjected to Mann-Whitney $U$ test to check for the statistical significance. The Spearman correlation coefficient test was used to investigate the correlation between the groups with typical/atypical CT features and mortality and also was used to investigate the correlation between the age and CT severity score among the patients with atypical CT features.

\section{Results}

A total of 298 reverse-transcriptase polymerase chain reaction (RT-PCR) confirmed COVID-19 pneumonia patients admitted between 1 July and 31 October 2020 were retrospectively evaluated. The demographics pertaining to age, gender, presenting symptoms, presence of comorbidities/risk factors, CT severity score, and disease outcome (alive or died) are as below.

The mean age in our cohort was $53.48 \pm 15.74$ years [range 9-90 years]. The age was further classified into 9 groups: (0-10), (11-20), (21-30), (31-40), (41-50), (51$60),(61-70),(71-80)$, and (81-90) as depicted in the Table 1 . The age group (51-60) had highest cases with total of 79 cases $(26.5 \%)$ There was predilection for males 234 (78.5\%) when compared to female 64 (21.5\%).
The most common presenting symptoms were fever $[n$ $=197(66.1 \%)]$ and cough $[n=139$ (46.6\%)]. Other symptoms were dyspnea, generalized weakness, myalgia and others with frequencies as depicted in the Table 2.

The comorbidities/risk factors considered were hypertension, diabetes mellitus, cerebrovascular diseases, and others as depicted in the Table 3. Comorbidities/risk factors were found in $161 / 298$ patients $(54.0 \%)$. The most common associations were diabetes mellitus $[n=$ $100(33.5 \%)]$ and hypertension $[n=94(31.5 \%]$.

Out of 298 cases of COVID-19 pneumonia, 218 cases (73.1\%) showed typical CT features while 63 cases $(21.1 \%)$ showed atypical CT features with concurrent classical findings and the remaining 17 cases (5.8\%) were normal. Among the atypical CT imaging features, pulmonary cysts were the most common feature in our study. Other various atypical imaging features with their incidences in our study are as depicted in the Table 4.

In our cohort, the pulmonary cysts on HRCT were well defined, thin walled $(2-4 \mathrm{~mm})$ and of size $<2.5 \mathrm{~cm}$. The most common pattern of distribution of pulmonary cysts was peripheral lung distribution $[n=23(85.2 \%)]$. Other patterns were random distribution $[n=3(11.1 \%)]$ and perihilar distribution $[n=1(3.7 \%)]$. They showed lower lobe predominance $(n=15)$ when compared to upper lobe $(n=9)$ and middle lobe $(n=2)$.

The nodules on HRCT showed peripheral subpleural distribution $[n=12]$. Only one case showed centrilobular distribution with tree in bud pattern. Both solid $(n=$ $6)$ and GGO $(n=7)$ nodules were equally seen. No difference in the lobar predominance [upper lobe $(n=6)$ and lower lobe $(n=7)]$.

Out of 17 cases of pleural effusion, 13 cases showed bilateral effusion. A total of 15 cases showed mild effusion and two showed moderate effusion. In 10 cases, there was no presence of other co-existent diseases while 7 cases had co-existent diseases.

Table 4 Incidences of the atypical CT findings of COVID-19 among the study group

\begin{tabular}{llll}
\hline SL no. & Atypical CT imaging features & Number of cases & Percentage (out of 298 cases) \\
\hline 1. & Pulmonary cysts & 27 & 9.0 \\
2. & Pleural effusion & 17 & 5.7 \\
3. & Nodules & 13 & 4.3 \\
4. & Bull's eye/target sign & 4 & 1.3 \\
5. & Cavitation & 3 & 1.0 \\
6. & Spontaneous pneumothorax & 2 & 0.6 \\
7. & Hilar lymphadenopathy & 2 & 0.6 \\
8. & Spontaneous pneumo-mediastinum, subcutaneous emphysema & 1 & 0.3 \\
9. & Halo sign & 1 & 0.3 \\
10 & Empyema & 1 & 0.3 \\
11. & Necrotizing pneumonia with abscess & 1 & 0.3 \\
\hline
\end{tabular}


Table 5 Atypical features of COVID-19 cases and their CT severity score

\begin{tabular}{lll}
\hline CT severity score (out of 25) & Total number(out of 63) & Percentage (\%) \\
\hline Mild $(<7)$ & 26 & 41.26 \\
Moderate (8-17) & 25 & 39.68 \\
Severe $(>18)$ & 12 & 19.04 \\
\hline
\end{tabular}

All four cases with the bull's eye sign/target sign were all peripherally located in the lower lobes.

All cases with cavitation $(n=3)$ showed peripheral distribution with two cases involving the lower lobe and one in the upper lobe.

Two cases showed bilaterally enlarged hilar group of lymph nodes with short axis diameter of $>10 \mathrm{~mm}$ with more on right side compared to left. Loss of hilar fat pad was noted in both the case.

\section{Correlation between atypical CT imaging features with age and severity}

Significant positive correlation between CT severity score among atypical group and age was observed in our study ( $\rho=0.343$ and $p=0.006$ ), indicating that with increase in age there was increase in the CT severity score and also of atypical CT features. Out of 63 patients with atypical features, CT severity score were as depicted in Table 5.

However, there was no statistically significant correlation $(p>0.05)$ between typical or atypical CT features and the severity of the disease (CT severity score).

In terms of clinical outcome, 289 patients (97\%) were discharged after clinical improvement and 9 patients (3\%) died in hospital at the time of the study. Out of 9 demises, CT severity was of moderate (score 8-17) and severe category (score $>18$ ). All cases were aged above the mean of 53.4 years and majority was associated with comorbidities $(n=8)$. Males $[n=7(78 \%)]$ were affected more compared to females $[n=2(22 \%)]$. However, no statistically significant association between typical or atypical CT features and mortality was noted $(p>0.05)$.

\section{Discussion}

Coronavirus disease 2019 (COVID-19) is caused by severe acute respiratory syndrome coronavirus 2 (SARS$\mathrm{CoV}-2)$. This has rapidly resulted in a worldwide pandemic with significant increase in morbidity and mortality [1]. The imaging changes in COVID-19 pneumonia are diverse with the various atypical CT features being less clearly described. The study conducted herein explains the atypical CT features in COVID-19 pneumonia.

In our study, the most common presenting symptoms were fever and cough consistent with the study by Shi $\mathrm{H}$ et al. [7]. There was predilection towards males (78.5\%) as seen in the study done by Huang $C$ et al. [8]. The other predisposing conditions in our study were elderly patients (mean 53.4 years) and comorbidities which are consistent with the study by Shi $\mathrm{H}$ et al. [7]. The mortality rate in our study was $3 \%$. All the deaths occurred in elderly patients who had comorbidities, consistent with

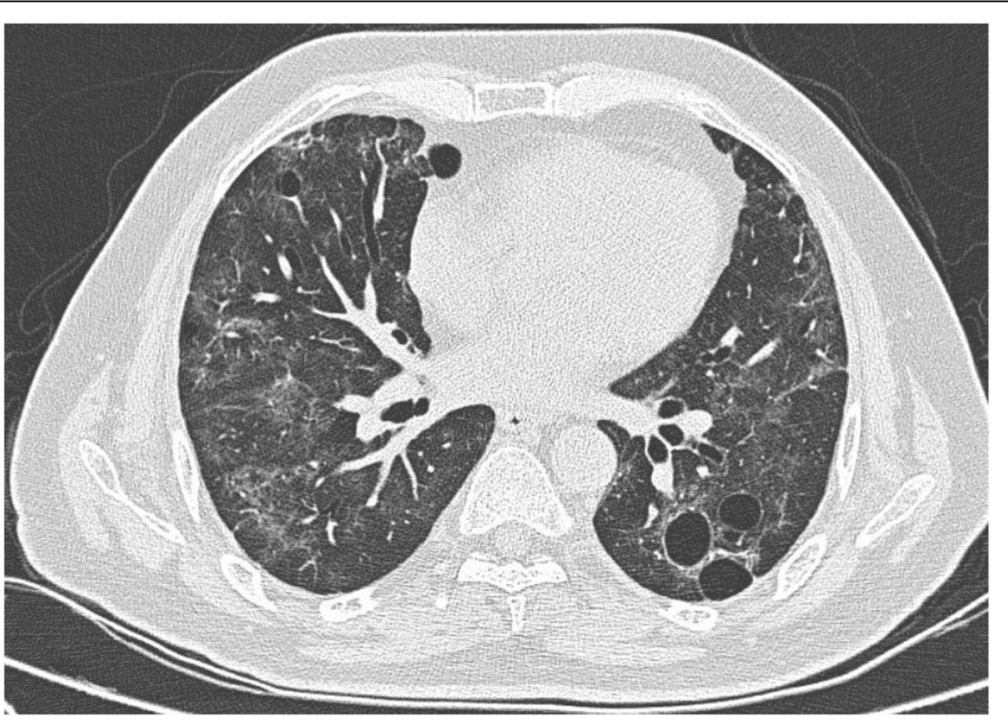

Fig. 1 Axial CT thorax of a 60-year-old COVID pneumonia patient showing multiple thin-walled air-filled cystic lesion in the bilateral lower lobes. Areas of GGOs with interlobular septal thickening are also seen 
previous reports (8) and had moderate-severe CT severity score. Hence, advanced age, male sex, presence of comorbidities and higher $\mathrm{CT}$ severity score might be risk factors for poor prognosis.

Based on current literature, the typical imaging features of COVID-19 pneumonia on CT include bilateral, multilobar GGOs with/without consolidation, and superimposed interlobar septal thickening [2,3]. They show a peripheral, posterior, and basilar distribution [2]. In our study, majority of the patients $(73.1 \%)$ showed typical CT features and only $21.1 \%$ patients showed atypical CT features with concurrent above classical findings. Among the atypical CT features, the most common was pulmonary cysts. The other features in the order of frequency included pleural effusion, nodules, bull's eye/ target sign, cavitation, spontaneous pneumothorax, hilar lymphadenopathy, spontaneous pneumo-mediastinum with subcutaneous emphysema, halo sign, empyema, and necrotizing pneumonia with abscess.

The incidence of pulmonary cysts in our study was $9.0 \%$ which is consistent with the study by Shi $\mathrm{H}$ et al. [7]. Recent studies speculate that the pulmonary cystic change in COVID-19 might be secondary to ischemic parenchymal damage, lung fibrosis and low lung compliance [9]. Another explanation is blockage of the bronchioles by mucus and mucus plugs followed by the overinflation of the alveoli and resultant rupturing of the alveolar septum with subsequent formation of small cysts
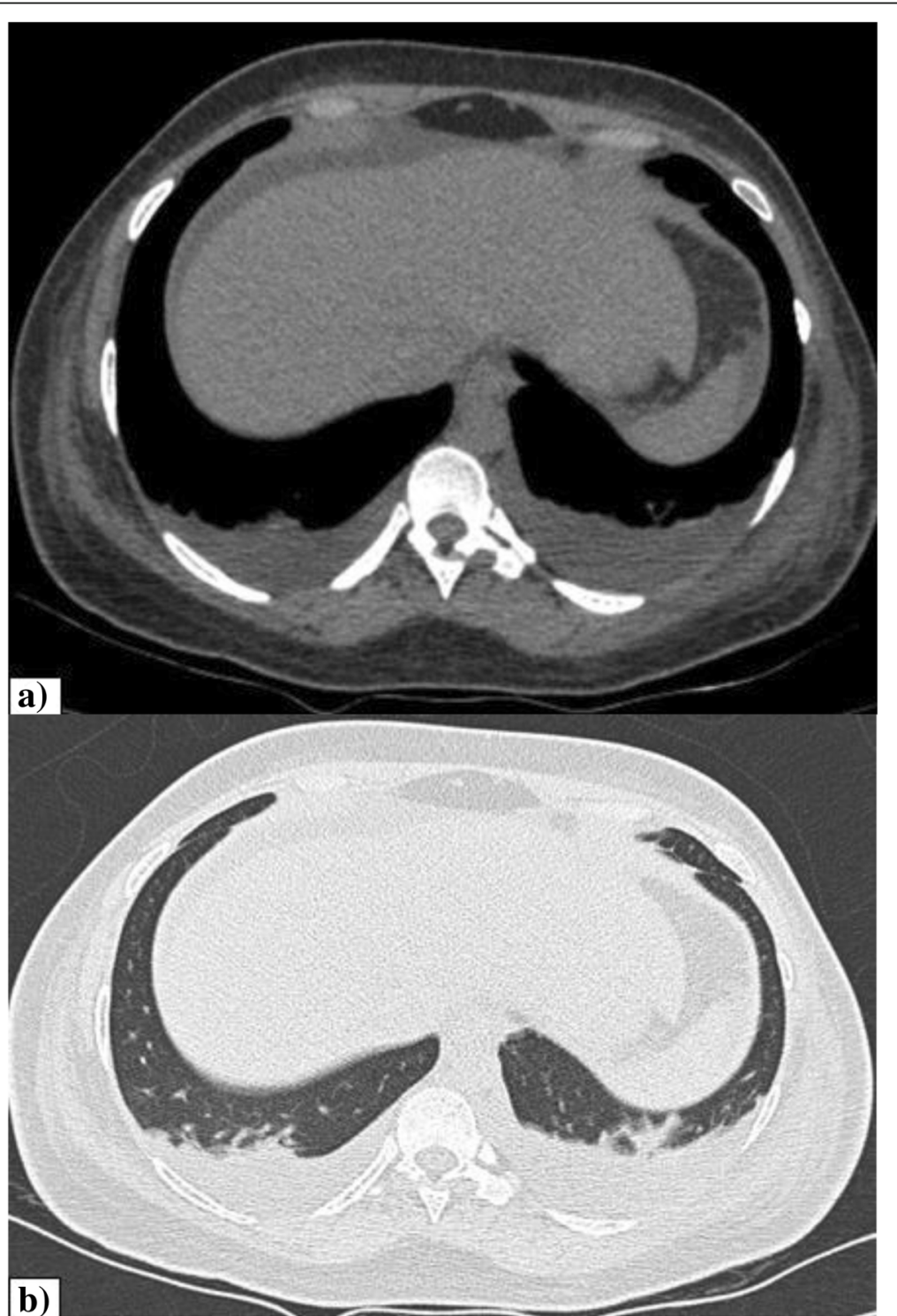

Fig. 2 Pleural effusion. a, b Axial CT thorax (mediastinal window and lung window) of a 38-year-old COVID pneumonia patient showing bilateral pleural effusion with underlying sub-segmental collapse 
[10]. None of the patients in our study were on mechanical ventilation and hence ruling out barotrauma induced cystic changes [9]. The peripheral subpleural cysts are prone to rupture causing pneumothorax. Hence, in COVID-19 pneumonia, prominent identification of pulmonary cysts and close monitoring for complications are required. Figure 1 shows pulmonary cysts in a case of COVID-19 pneumonia.

The incidence of pleural effusion in our study was $5.7 \%$. However the incidence of pleural effusion in COVID-19 has been reported to be varying as per the available literature [11]. According to the study by Shi et al., the prevalence of pleural effusion varies depending on the stage of the disease, with a reported prevalence of $13 \%$ in the third week after onset of symptoms [7]. Pleural effusion may also be predictive of worse prognosis [11]. The presence or absence of underlying medical conditions, study setting, disease stage, and concurrent superimposed bacterial pneumonia are to be considered in order to comment on the prevalence and etiology of pleural effusion in COVID-19 infection [12]. The presence of effusion in cases with no concurrent comorbidities can possibly be attributed to COVID-19 infection or superadded bacterial infection. Figure 2 shows bilateral pleural effusion in a case of COVID-19 pneumonia.

The bull's eye/target sign consists of central ground glass opacity surrounded by an inner ring of air and an outer ring of ground glass as shown in Fig. 3. It is presumed that bull's eye sign may be a variant of the reverse halo sign [13]. In our study, bull's eye sign accounted to $1.3 \%$ of the cases. Only few case reports on COVID-19 with bull's eye sign has been made in the literature [13-
15]. It has been theorized that they represent regions of organizing pneumonia, with perilobular involvement and a tendency to be located peripherally within the lung parenchyma [13]. The bull's eye sign/target sign in the presented cases likewise were all peripherally located in the lower lobes [13].

Lung cavitation due to COVID-19 pneumonia is an uncommon finding which usually is seen in the late stage $[16,17]$. The incidence in our study was $1 \%$. There are few reports of intrapulmonary cavities of COVID19-infection [11, 16, 18, 19]. However majority of other reviews showed no cavitation in their study [7, 20-23]. The cavitation may be related to diffuse alveolar damage, intra-alveolar hemorrhage, and necrosis of parenchymal cells based on prior autopsy reports [24, 25]. Common causes of cavitary lung lesions must be investigated appropriately in all patients [26]. In our study, there was no laboratory evidence supporting bacterial infections. Hence, the possibility of COVID-19 independently resulting in cavitation is to be considered. Close monitoring is required for complications like hemorrhage within the cavity, rupture of peripheral cavity resulting in pneumothorax, and superadded bacterial infection resulting in an abscess. Figure 4 shows pulmonary cavity with clots in a case who presented with hemoptysis.

Spontaneous pneumomediastinum (SPM) refers to the presence of air in the mediastinum occurring in the absence of traumatic or an iatrogenic origin [2, 27]. In current limited research, only few case reports of SPM in COVID-19 have been made [2, 28-30]. The incidence of SPM in our study was $0.3 \%$ and isolated spontaneous pneumothorax was $0.6 \%$. Chen $\mathrm{N}$ et al. showed

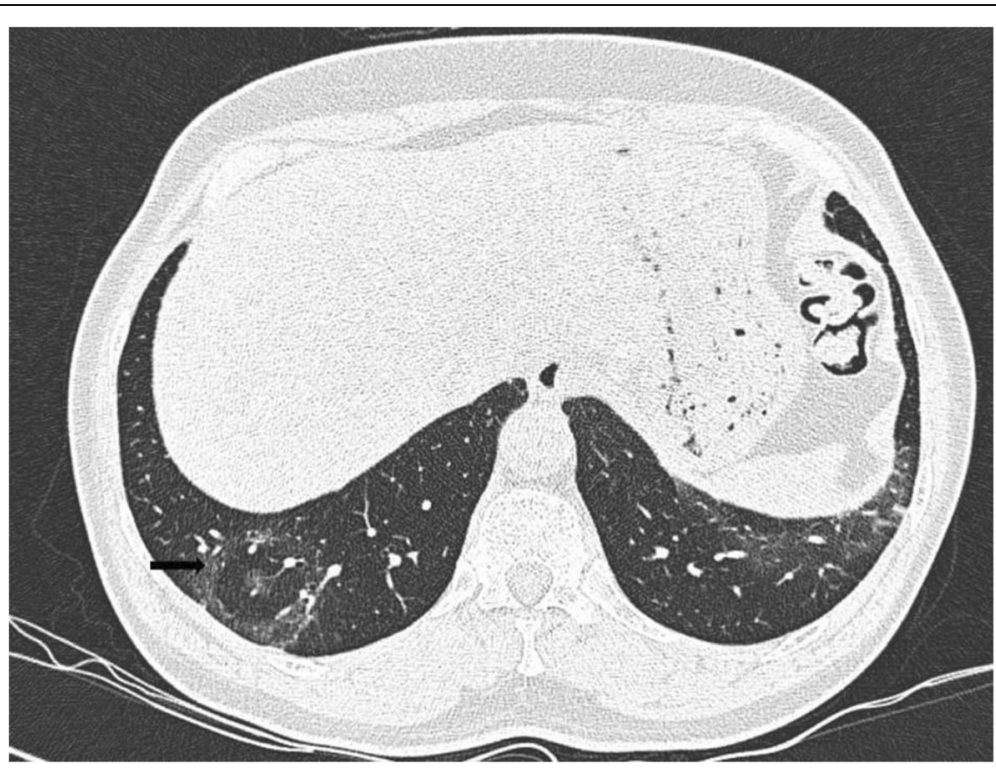

Fig. 3 Bull's eye sign. Axial CT thorax of a 55-year-old COVID pneumonia patient showing central ground glass opacity surrounded by an inner ring of air and an outer ring of ground glass in the right lower lobe 


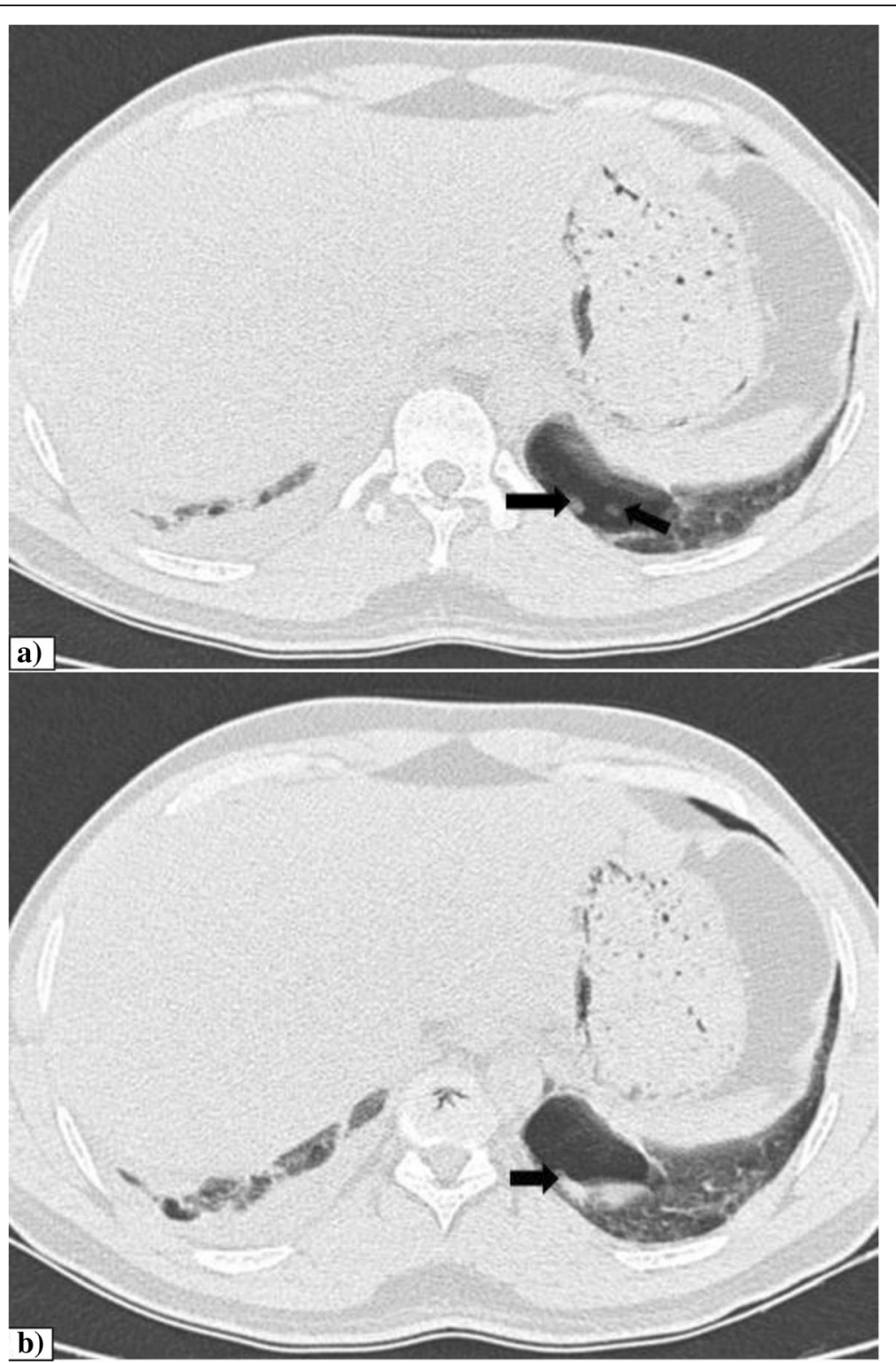

Fig. 4 Pulmonary cavity with clots. a, b Contiguous sections of axial CT thorax of a 35-years-old COVID pneumonia patient who presented with hemoptysis, showing thin wall cavity in the posterior basal segment of left lobe with soft tissue component of hemorrhagic density as indicated by the arrows. Right pleural effusion is also seen

incidence of isolated spontaneous pneumothorax of $1 \%$ in COVID-19 patients [20]. It is believed that the possible causes of SPM in COVID-19 were similar to those in SARS showing severe diffuse alveolar damage. This diffuse alveolar damage results in alveolar rupture which can be further precipitated by high interalveolar pressure caused by factors like artificial ventilation, coughing or straining. This results in air migration into the mediastinum through the Macklin effect $[2,31-33]$. The SPM can lead to other complications such as pneumothorax, extensive subcutaneous emphysema, and an uncommon complication of lung infections [2]. In our study, none of the cases were mechanically ventilated at the time of initial CT imaging. One case with emphysematous changes showed SPM with pneumothorax and extensive subcutaneous emphysema as shown in the Fig. 5, which we believe would have occurred due to progression of preexisting lung lesions resulting in rupture of subpleural bulla or secondary to alveolar rupture as described above. Isolated spontaneous pneumothorax in our study might be secondary to rupture of subpleural pulmonary cysts or due to alveolar rupture.

The halo sign represents area of consolidation/pulmonary nodule/mass surrounded by ground-glass 

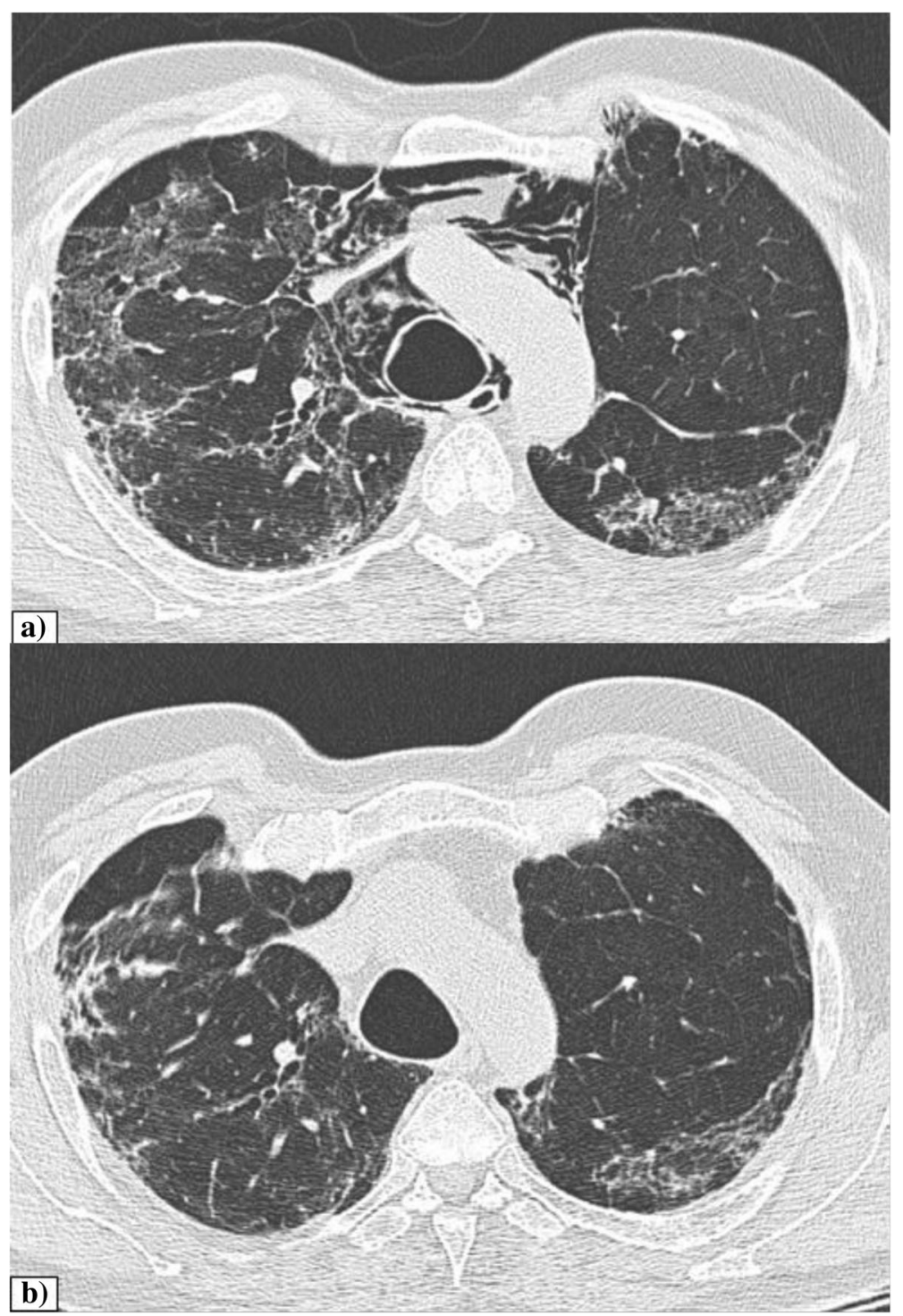

Fig. 5 Spontaneous pneumomediastinum. a Axial CT thorax of a 58-year-old COVID pneumonia patient showing pneumomediastinum in the pre-vascular space and around trachea and esophagus. Visualized lung shows peripheral GGOs with interlobular septal thickening. b Complete resolution of pneumo-mediastinum after 10 days

opacity [34-36] as shown in the Fig. 6. The incidence of halo sign in our study was $0.3 \%$. In current limited research, only few cases reports on the halo sign has been made in COVID-19 [11, 37, 38]. Based on the pathological findings as seen in some recent studies, extensive thrombotic damage of the pulmonary microcirculation can explain the "halo sign" of consolidations [34].

The incidence of hilar lymphadenopathy in our study was $0.6 \%$. In the available current literature, only one case report with hilar lymphadenopathy has been reported in COVID-19 [39]. Few studies showed no presence of hilar lymphadenopathy in COVID-19 [21, 40]. Thoracic lymphadenopathy includes hilar and mediastinal group of lymph nodes. Mediastinal lymphadenopathy previously thought to be an atypical feature has been redefined as "not-atypical" feature of COVID-19 [7, 41]. However, hilar lymphadenopathy which is usually associated with fungal infections, mycobacterial infections, and sarcoidosis are seldom seen in COVID pneumonia [39]. Histopathological correlation was unavailable for our cases. Hence, bacterial or fungal co-infection cannot be ruled. Follow-up imaging is to be done to evaluate the persistence or resolution of hilar lymphadenopathy and is required to establish their clinical importance.

In our study, the incidence of pulmonary nodules was 4.3\%. The reported incidence of nodules in COVID-19 has been found to be varying, $3 \sim 13 \%$ as per the 


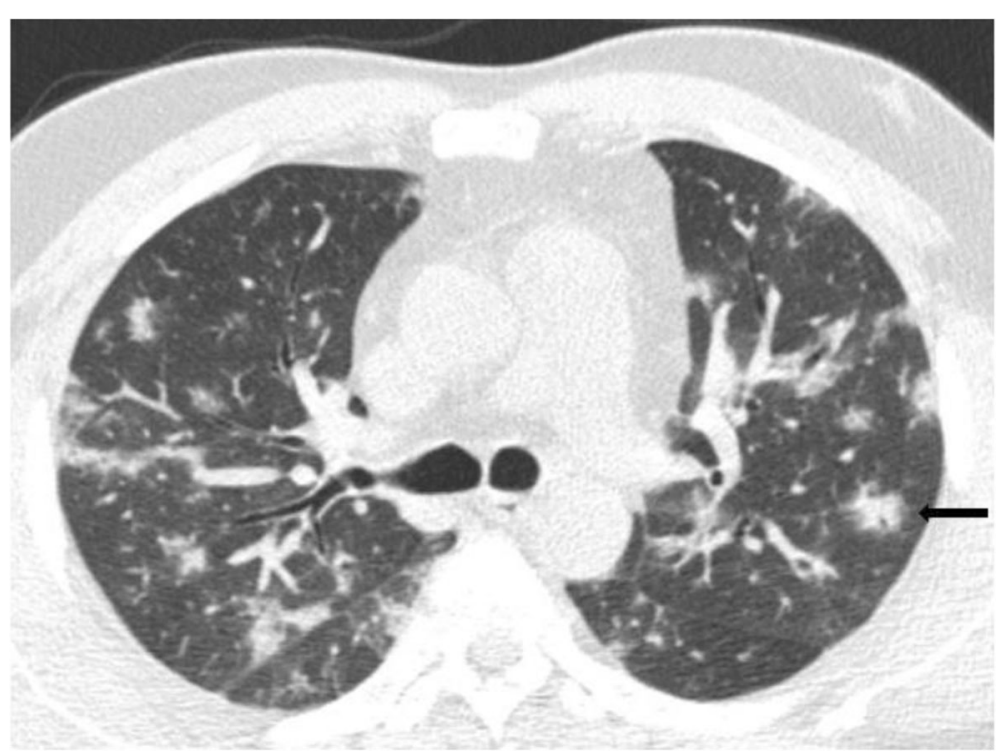

Fig. 6 Halo sign. Axial CT thorax of a 40-year-old COVID pneumonia patient showing multiple bilateral patchy consolidations with surrounding ground-glass opacities as indicated by the arrow

available literature [42, 43]. The relation between COVID-19 and nodules are not fully understood. Further studies are required to know whether these are incidental nodules or atypical manifestation of COVID-19 pneumonia. Figure 7 shows a case with GGO nodule.

Empyema has significant clinical morbidity [44]. In our study, a case presented with loculated hydropneumothorax as shown in the Fig. 8. Later, pus-like pleural fluid was aspirated and sent for analysis which showed elevated glucose, protein, and chlorides with predominant neutrophils (90\%). This confirms the superadded bacterial infection in COVID-19 pneumonia resulting in empyema. Isolated empyema in COVID-19 is seldom reported in the literature.

Necrotizing pneumonia is a severe complication of lung infection characterized by necrosis and liquefaction of lung parenchyma, likely secondary to ischemia caused by thrombosis of intrapulmonary vessels [45]. In viral pneumonias, necrotizing processes with development of cavities and air-fluid level in the initial

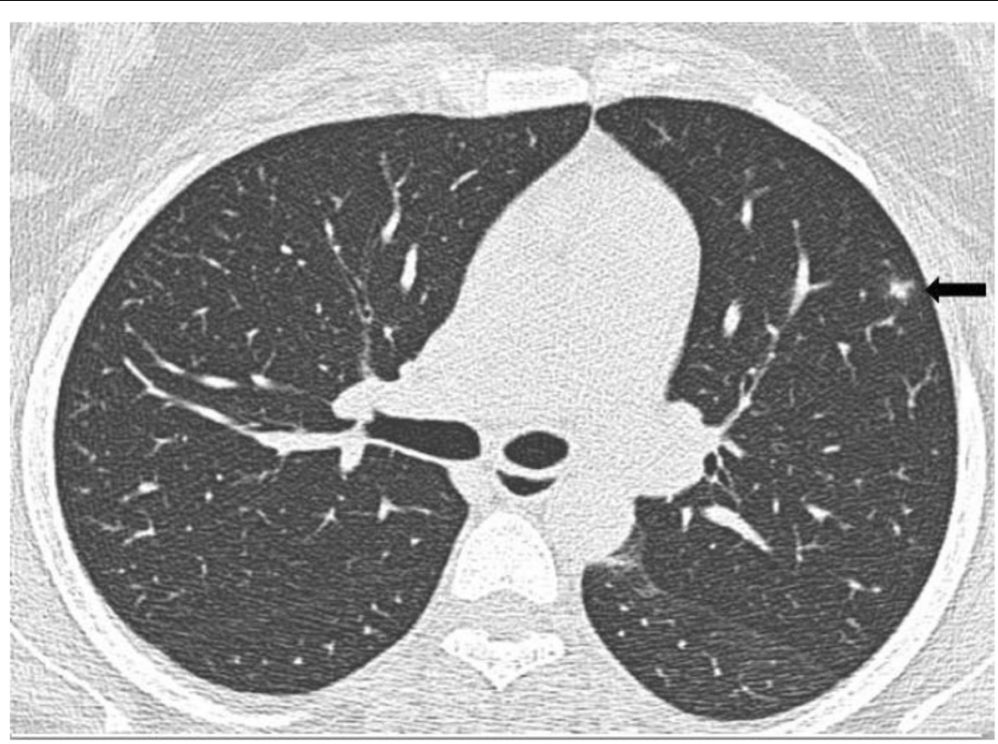

Fig. 7 GGO nodule. Axial CT thorax of a 35-year-old COVID pneumonia patient showing small solitary GGO nodule in the left upper lobe as indicated by the arrow 


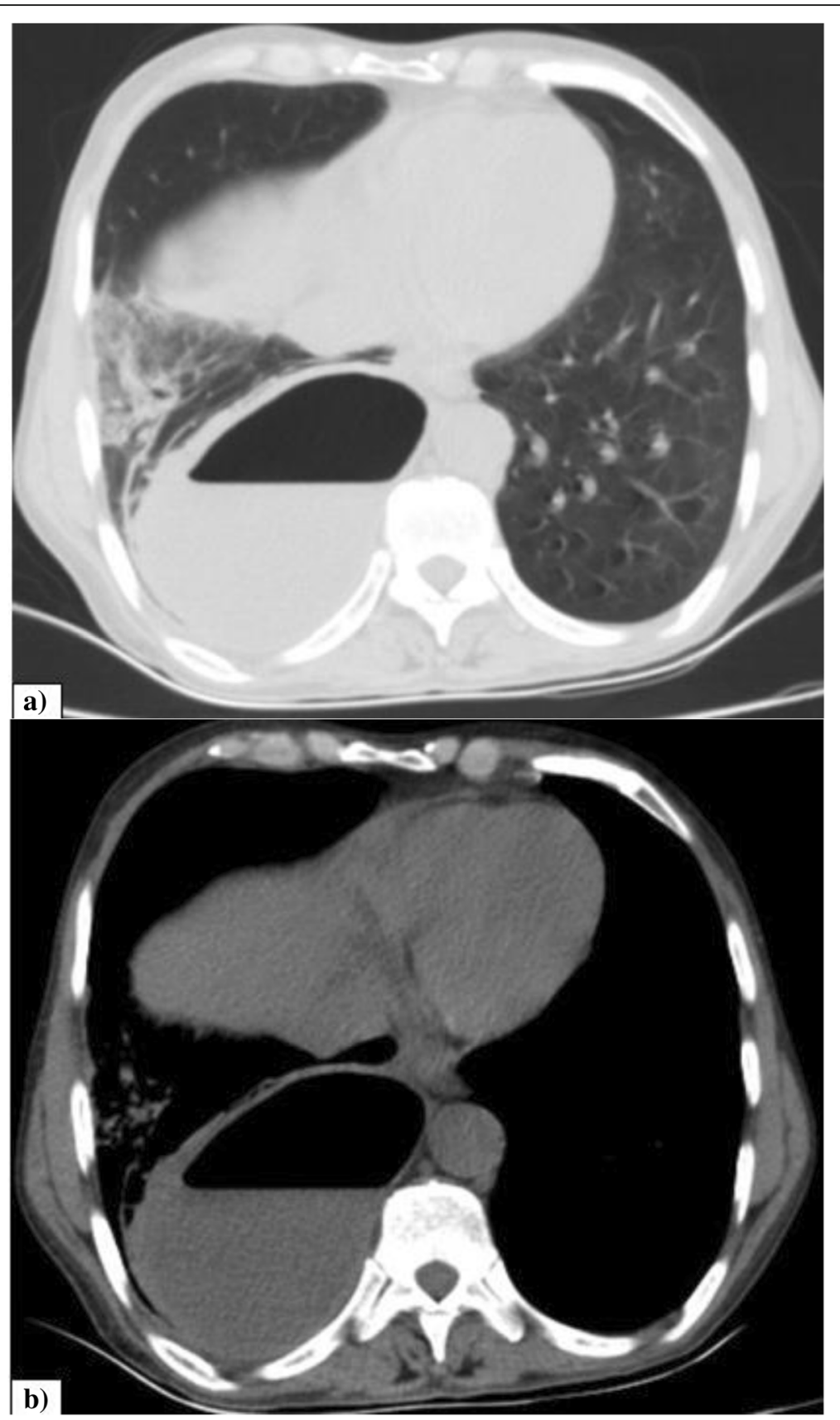

Fig. 8 Empyema. a, b Axial CT thorax (lung window and mediastinal window) of a 63-year-old COVID pneumonia patient showing right sided loculated empyema. Adjacent areas of consolidation are also seen

areas of consolidation have been described before in the literature [46]. Similarly, COVID-19 which causes small vessel microthrombi and severe dysregulation of the host immune reaction can result in necrotizing pneumonia. Although bacterial and fungal lung abscesses are known to occur in COVID-19 in up to $11 \%$ and $3 \%$, respectively, which were presumed to have formed after hospital admission [47]. Our study showed an incidence of only $0.3 \%$. This discrepancy might be due to the differences in demographic features and hospital care. Figure 9 shows a case of necrotizing pneumonia with secondary cavitation and abscess formation.

\section{Conclusion}

During the course of the pandemic, much of the literature published describes the classical imaging features encountered in COVID-19, with anecdotal references 

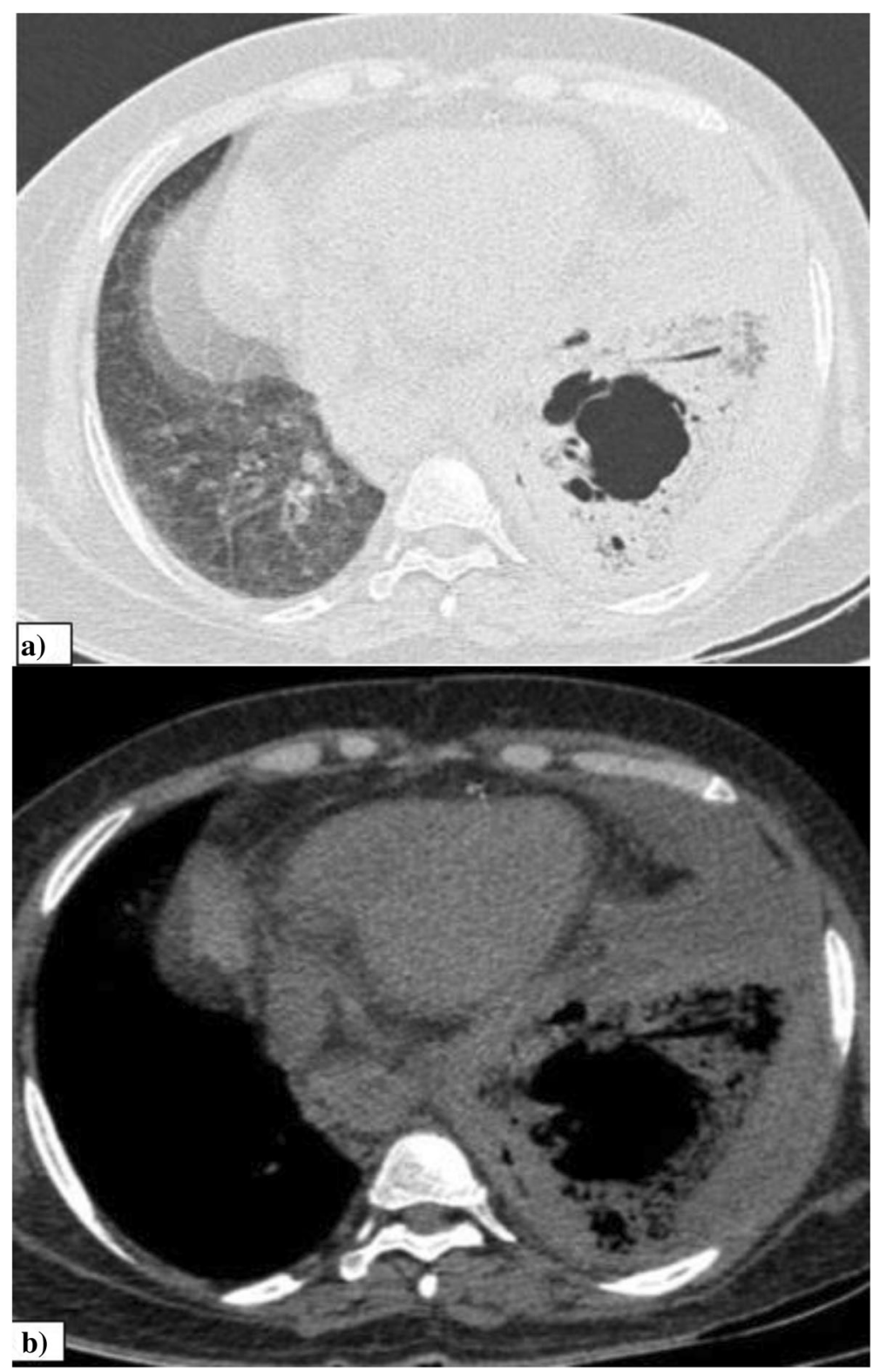

Fig. 9 Necrotizing pneumonia. a, b Axial CT thorax (lung window and mediastinal window) of a 51-year-old COVID pneumonia patient areas of cavitation in the background of consolidation in the left lower lobe. Left pleural effusion also noted

made to the atypical CT imaging features. A small subset of cases with COVID-19 pneumonia show diverse imaging manifestations, which if ignorant can confound the clinical approach to the patient leading to misdiagnosis. The present study aimed not only to illustrate the various atypical CT features in COVID-19 pneumonia but also correlated with disease severity. The atypical features observed includes pulmonary cystic changes, pleural effusion, nodules, bull's eye/target sign, cavitation, halo sign, hilar lymphadenopathy, spontaneous pneumothorax, spontaneous pneumo-mediastinum, empyema and necrotizing pneumonia with abscess.
Significant positive correlation between CT severity score among atypical group and age was observed in our study indicating that with increase in age there was increase in the CT severity score and also of atypical CT features. Thus, a comprehensive knowledge of these atypical pulmonary presentations and its complications on imaging plays an important role in the early diagnosis and management of COVID-19.

\section{Abbreviations}

CT: Computed tomography; Covid-19: Coronavirus disease 2019;

GGO: Ground glass opacity; RT-PCR: Reverse-transcriptase polymerase Chain reaction; SARS-CoV-2: Severe acute respiratory syndrome coronavirus 2; 
PACS: Picture Archiving and Communication Systems; HRCT: High-resolution computed tomography; MDCT: Multidetector computed tomography; SPM: Spontaneous pneumo-mediastinum

\section{Acknowledgements}

I sincerely thank our esteemed institution JSS Academy of Higher Education and Research, Mysore, for encouraging and providing support in all our endeavors. I also take this opportunity to express my gratitude to all the faculty, post graduates, technical and supporting staff of Department of Radiology.

\section{Authors' contributions}

Dr BG — study conception and design, analysis, and interpretation of data draft manuscript preparation. Dr SDK—study conception and design, analysis, and interpretation of data. Dr RH-supervision of the project, analysis, and interpretation of data. Dr SS—draft manuscript preparation. Dr AH—data collection. TG—data collection. All authors discussed the results and contributed to the final manuscript. All authors read and approved the final manuscript.

\section{Funding}

Not applicable.

\section{Availability of data and materials}

The datasets generated and/or analyzed during the current study are not publicly available due to privacy of the study participants.

\section{Declarations}

\section{Ethics approval and consent to participate}

This study is approved by the Ethics committee of the JSS Academy of Higher Education and Research, Mysore, Karnataka, India. Only anonymous patient details were used for data collection and analysis. No interventions were done. The Institutional Ethics committee's reference number-JSSMC/ IEC/231220/04 NCT/2020-21 dated on 24 December 2020.

\section{Consent for publication}

Not applicable.

\section{Competing interests}

The authors declare that they have no competing interests.

\section{Received: 2 December 2020 Accepted: 22 February 2021} Published online: 04 March 2021

\section{References}

1. Revzin MV, Raza S, Warshawsky R, D'Agostino C, Srivastava NC, Bader AS et al (2020) Multisystem imaging manifestations of COVID-19, part 1: viral pathogenesis and pulmonary and vascular system complications. Radiographics. 40(6):1574-1599. https://doi.org/10.1148/rg.2020200149

2. Brogna B, Bignardi E, Salvatore P, Alberigo M, Brogna C, Megliola A et al (2020) Unusual presentations of COVID-19 pneumonia on CT scans with spontaneous pneumomediastinum and loculated pneumothorax: a report of two cases and a review of the literature. Heart Lung. 49(6):864-868. https://doi.org/10.1016/j.hrtlng.2020.06.005

3. Yadav R, Sahoo D, Graham R (2020) Thoracic imaging in COVID-19. Cleve Clin J Med. 87(8):469-476. https://doi.org/10.3949/ccjm.87a.ccc032

4. Bernheim A, Mei X, Huang M, Yang Y, Fayad ZA, Zhang $N$ et al (2020) Chest CT Findings in coronavirus disease 2019 (COVID-19): relationship to duration of infection. Radiology 295:685-691. https://doi.org/10.1148/ radiol.2020200463

5. Simpson S, Kay FU, Abbara S, Bhalla S, Chung JH, Chung M et al (2020) Radiological Society of North America Expert Consensus Statement on reporting chest $C T$ findings related to COVID-19. Endorsed by the Society of Thoracic Radiology, the American College of Radiology, and RSNA Secondary Publication. J Thorac Imaging. 35(4):219-227. https://doi.org/10.1 097/RTI.0000000000000524

6. Saeed GA, Gaba W, Shah A, Helali AAA, Raidullah E, Ali ABA et al (2020) Correlation between chest $C T$ severity scores and the clinical parameters of adult patients with COVID-19 pneumonia. medRxiv. https://doi.org/10.11 01/2020.10.15.20213058
7. Shi H, Han X, Jiang N, Cao Y, Alwalid O, Gu J et al (2020) Radiological findings from 81 patients with COVID-19 pneumonia in Wuhan, China: a descriptive study. Lancet Infect Dis. https://doi.org/10.1016/S1473-3099(20)3 0086-4

8. Huang C, Wang Y, Li X, Ren L, Zhao J, Hu Y et al (2020) Clinical features of patients infected with 2019 novel coronavirus in Wuhan. China. Lancet. 395(10223):497-506. https://doi.org/10.1016/50140-6736(20)30183-5

9. Liu K, Zeng Y, Xie P, Ye X, Xu G, Liu J et al (2020) COVID-19 with cystic features on computed tomography: a case report. Medicine 99, 18(e20175). https://doi.org/10.1097/MD.0000000000020175

10. Chen J, Peng S, Zhang B, Liu Z, Liu L, Zhang W (2020) An uncommon manifestation of COVID-19 pneumonia on CT scan with small cavities in the lungs: a case report. Medicine 99, 28(e21240). https://doi.org/10.1097/MD. 0000000000021240

11. Ye Z, Zhang Y, Wang Y, Huang Z, Song B (2020) Chest CT manifestations of new coronavirus disease 2019 (COVID-19): a pictorial review. Eur Radiol: 4381-4389. https://doi.org/10.1007/s00330-020-06801-0

12. Aujayeb A Clarification on pleural effusions in COVID-19. Radiol Cardiothoracic Imaging 2(3):e200330. https://doi.org/10.1148/ryct.2020200330

13. McLaren TA, Gruden JF, Green DB The bullseye sign: a variant of the reverse halo sign in COVID-19 pneumonia. Clinical Imaging 68(2020):191-196. https://doi.org/10.1016/j.clinimag.2020.07.024

14. Wu Y, Xie YL, Wang X (2020) Longitudinal CT findings in COVID-19 pneumonia: case presenting organizing pneumonia pattern. Radiology: Cardiothoracic Imaging. 2(1):e200031. https://doi.org/10.1148/ryct.2020200031

15. Shaghaghi S, Daskareh M, Irannejad M, Shaghaghi M, Kamel IR (2021) Target-shaped combined halo and reversed-halo sign, an atypical chest CT finding in COVID-19. Clin Imaging. 69:72-74. https://doi.org/10.1016/j.clinima g.2020.06.038

16. Muheim M, Weber FJ, Muggensturm P, Seiler E (2020) An unusual course of disease in two patients with COVID-19: pulmonary cavitation. BMJ Case Rep 13(9). https://doi.org/10.1136/bcr-2020-237967

17. Chen Y, Chen W, Zhou J, Sun C, Lei Y (2020) Large pulmonary cavity in COVID-19 cured patient case report. Ann Palliat Med. https://doi.org/10.2103 7/apm-20-452

18. Kong W, Agarwal PP (2020) Chest imaging appearance of COVID-19 infection. Radiol Cardiothoracic Imaging. 2(1):e200028. https://doi.org/10.114 8/ryct.2020200028

19. Xu Z, Pan A, Zhou H et al (2020) Rare CT feature in a COVID-19 patient: cavitation. Diagn Interv Radiol. 26(4):380-381. https://doi.org/10.5152/dir.202 0.20181

20. Chen N, Zhou M, Dong X, Qu J, Gong F, Han Y et al (2020) Epidemiological and clinical characteristics of 99 cases of 2019 novel coronavirus pneumonia in Wuhan, China: a descriptive study. Lancet. 395(10223):507-513. https:// doi.org/10.1016/S0140-6736(20)30211-7

21. Chung M, Bernheim A, Mei X, Zhang N, Huang M, Zeng X et al (2020) CT imaging features of 2019 novel coronavirus (2019-nCoV). Radiology. 295(1): 202-207. https://doi.org/10.1148/radiol.2020200230

22. Hu Q, Guan H, Sun Z, Huang L, Chen C, Ai T et al (2020) Early CT features and temporal lung changes in COVID-19 pneumonia in Wuhan. China. Eur J Radiol. 128:109017. https://doi.org/10.1016/j.ejrad.2020.109017

23. Zhou Z, Guo D, Li C, Fang Z, Chen L, Yang R et al (2020) Coronavirus disease 2019: initial chest CT findings. Eur Radiol. 30(8):4398-4406. https:// doi.org/10.1007/s00330-020-06816-7

24. Menter T, Haslbauer JD, Nienhold R, Savic S, Hopfer H, Deigendesch N et al (2020) Post-Mortem examination of COVID19 patients reveals diffuse alveolar damage with severe capillary congestion and variegated findings of lungs and other organs suggesting vascular dysfunction. Histopathology:77, 198-209. https://doi.org/10.1111/his.14134

25. Yao XH, Li TY, He ZC, Ping YF, Liu HW, Yu SC et al (2020) A pathological report of three COVID-19 cases by minimal invasive autopsies. Zhonghua Bing Li Xue Za Zhi. 49(5):411-417. https://doi.org/10.3760/cma.j.cn112151-2 0200312-00193

26. Selvaraj V, Dapaah-Afriyie K (2020) Lung cavitation due to COVID-19 pneumonia. BMJ Case Rep 13:e237245. https://doi.org/10.1136/bcr-2020-237245

27. Sahni S, Verma S, Grullon J, Esquire A, Patel P, Talwar A (2013) Spontaneous pneumomediastinum: time for consensus. N Am J Med Sci. 5:460-464. https://doi.org/10.4103/1947-2714.117296

28. Zhou C, Gao C, Xie Y, Xu M (2020) COVID-19 with spontaneous pneumomediastinum. Lancet Infect Dis. 20(4):510. https://doi.org/10.1016/ S1473-3099(20)30156-0 
29. Wang W, Gao R, Zheng Y, Jiang L (2020) COVID-19 with spontaneous pneumothorax, pneumomediastinum and subcutaneous emphysema. J Travel Med 27(5). https://doi.org/10.1093/jtm/taaa062

30. Sun R, Liu H, Wang X (2020) Mediastinal emphysema, giant bulla, and pneumothorax developed during the course of COVID-19 pneumonia. Korean J Radiol. 21(5):541-544. https://doi.org/10.3348/kjr.2020.0180

31. Shan S, Guangming L, Wei L, Xuedong Y (2020) Spontaneous pneumomediastinum, pneumothorax and subcutaneous emphysema in COVID-19: case report and literature review. Rev Inst Med Trop Sao Paulo. 62:e76. https://doi.org/10.1590/S1678-9946202062076

32. Wintermark M, Schnyder P (2001) The Macklin effect: a frequent etiology for pneumomediastinum in severe blunt chest trauma. Chest. 120(2):543-547. https://doi.org/10.1378/chest.120.2.543

33. Chu CM, Leung YY, Hui JY, Hung IF, Chan VL, Leung WS et al (2004) Spontaneous pneumomediastinum in patients with severe acute respiratory syndrome. Eur Respir J. 23(6):802-804. https://doi.org/10.1183/09031936.04. 00096404

34. Poerio A, Sartoni M, Lazzari G, Valli M, Morsiani M, Zompatori M (2020) Halo, Reversed halo, or both? Atypical computed tomography manifestations of coronavirus disease (COVID-19) pneumonia: the "Double Halo Sign". Korean J Radiol 21(10):1161-1164. https://doi.org/10.3348/kjr.2020.0687

35. Hansell DM, Bankier AA, MacMahon H, McLoud TC, Müller NL, Remy J (2008) Fleischner Society: glossary of terms for thoracic imaging. Radiology. 246(3): 697-722. https://doi.org/10.1148/radiol.2462070712

36. Primack SL, Hartman TE, Lee KS, Müller NL (1994) Pulmonary nodules and the CT halo sign. Radiology. 190(2):513-515. https://doi.org/10.1148/ra diology.190.2.8284408

37. Li X, Zeng X, Liu B, Yu Y (2020) COVID-19 infection presenting with CT halo sign. Radiol Cardiothorac Imaging. 2(1):e200026. https://doi.org/10.1148/ ryct.2020200026

38. Farias LPG, Pereira HAC, Anastacio EPZ, Minenelli FF, Teles GBDS (2020) The halo sign as a chest computed tomography finding of COVID-19. Einstein (Sao Paulo) 18:eAl5742. https://doi.org/10.31744/einstein_journal/2020A 15742

39. Mughal MS, Rehman R, Osman R, Kan N, Mirza H, Eng MH (2020) Hilar lymphadenopathy, a novel finding in the setting of coronavirus disease (COVID-19): a case report. J Med Case Rep. 14(1):124. https://doi.org/10.11 86/s13256-020-02452-3

40. Ng MY, Lee EY, Yang J, Yang F, Li X, Wang H, Lui MM, Lo CS, Leung B, Khong PL, Hui CK (2020) Imaging profile of the COVID-19 infection: radiologic findings and literature review. Radiol Cardiothorac Imaging. 2(1): e200034. https://doi.org/10.1148/ryct.2020200034

41. Valette X, du Cheyron D, Goursaud S (2020) Mediastinal lymphadenopathy in patients with severe COVID-19. Lancet Infect Dis. 20(11):1230. https://doi. org/10.1016/S1473-3099(20)30310-8

42. Ai T, Yang Z, Hou H, Zhan C, Chen C, Lv W et al (2020) Correlation of chest CT and RT-PCR testing for coronavirus disease 2019 (COVID-19) in China: A Report of 1014 Cases. Radiology. 296(2):E32-E40. https://doi.org/10.1148/ra diol.2020200642

43. Xiong Y, Sun D, Liu Y, Fan Y, Zhao L, Li X et al (2020) Clinical and highresolution CT features of the COVID-19 infection: comparison of the initial and follow-up changes. Invest Radiol. 55(6):332-339. https://doi.org/10.1097/ RLI.0000000000000674

44. Mangete ED, Kombo BB, Legg-Jack TE (1993) Thoracic empyema: a study of 56 patients. Arch Dis Child. 69(5):587-588. https://doi.org/10.1136/adc.69.5. 587

45. Ooi SY, Lee SW (2017) Necrotising pneumonia: A pneumonia that may need surgical intervention. Med J Malaysia. 72(6):367-369

46. Koo HJ, Lim S, Choe J, Choi SH, Sung H, Do KH (2018) Radiographic and CT features of viral pneumonia. Radiographics. 38(3):719-739. https://doi.org/1 $0.1148 / \mathrm{rg} .2018170048$

47. Carsana L, Sonzogni A, Nasr A, Rossi RS, Pellegrinelli A, Zerbi P et al (2020) Pulmonary post-mortem findings in a series of COVID-19 cases from northern Italy: A two-centre descriptive study. Lancet Infect Dis. 20(10) 1135-1140. https://doi.org/10.1016/51473-3099(20)30434-5

\section{Publisher's Note}

Springer Nature remains neutral with regard to jurisdictional claims in published maps and institutional affiliations.

\section{Submit your manuscript to a SpringerOpen ${ }^{\circ}$ journal and benefit from:}

- Convenient online submission

- Rigorous peer review

- Open access: articles freely available online

- High visibility within the field

- Retaining the copyright to your article

Submit your next manuscript at $\boldsymbol{\nabla}$ springeropen.com 